\title{
$\mathrm{S}$ 중, 고등학생의 구강검진에 따른 구강 증상 및 구강건강행태 조사 홍민희 ${ }^{1}$, 정미애 ${ }^{*}$ \\ ${ }^{1}$ 강원대학교 치위생학과
}

\section{A Study on Oral Symptoms and Oral Health Behavior among Secondary Students}

\author{
Min-Hee Hong ${ }^{1}$ and Mi-As Jeong ${ }^{1 *}$ \\ ${ }^{1}$ Department of Dental Hygiene kangwon National University
}

\begin{abstract}
요 약 본 연구는 서울시에 소재한 S중학교 1학년 251명, S남자고등학교 1학년 220명을 대상으로 구강검진을 실시 한 결과 아래와 같다.

구강증상에 대한 중, 고등학생들의 치아 지각과민 경험은 고등학생이 $23.2 \%$ 로 중학생 $14.3 \%$ 보다 차갑고 뜨거운 음 료 혹은 음식을 마시거나 먹을 때 치아가 아픈 경험이 있었으며, 유의한 차이를 보였다 $\left(x^{2}=6.08, \mathrm{p}<.05\right)$. 치아 통증에 대한 경험은 고등학생이 $9.1 \%$ 로 중학생 $4.4 \%$ 보다 치아가 쑤시고 욱신거리고 아픈 경험이 있었으며, 유의한 차이를 보였다 $\left(x^{2}=4.23, \mathrm{p}<.05\right)$. 중학생과 고등학생의 구강건강행태 결과 중학생이 $48.6 \%$ 로 고등학생 $26.4 \%$ 보다 지난 1 년 간 치과병원을 간 적이 더 높게 나타났으며, 통계적으로도 유의한 차이를 보였다 $\left(x^{2}=24.56, p<.001\right)$. 하루 동안 잇솔 질 시기는 중학생이 $68.5 \%$ 로 고등학생 $57.3 \%$ 보다 아침식사 후에 이를 많이 닦았으며 $\left(x^{2}=6.39, \mathrm{p}<.05\right)$, 점심식사 후 에는 고등학생이 $16.8 \%$ 로 중학생 $7.2 \%$ 보다 이를 많이 닦았으며, 통계적으로도 유의한 차이를 보였다 $\left(x^{2}=10.58\right.$, $\mathrm{p}<.01$ ). 또한 중학생과 고등학생의 구강검사 판정결과 고등학생이 $44.1 \%$ 로 중학생 $22.3 \%$ 보다 우식치아가 많았으며 $\left(x^{2}=25.36, \mathrm{p}<.001\right)$, 중학생이 $9.6 \%$ 로 고등학생 $4.1 \%$ 보다 상실치아가 더 많았고, 통계적으로도 유의한 차이를 보였다 $\left(x^{2}=5.39, \mathrm{p}<.05\right)$.
\end{abstract}

\begin{abstract}
This study carried out dental checkup targeting 251 students in the 1st grade of S middle school and 220 students in the 1st grade of S high school in Seoul Metropolis. The results are as follows.

As for the experience of dental hypersensitivity to oral symptoms in middle-and-high school students, $23.2 \%$ of high school students had experience of painful tooth when drinking or eating cold and hot beverage or food, compared to $14.3 \%$ of middle school students, and showed significant difference $\left(\chi^{2}=6.08, \mathrm{p}<.05\right)$. As for the experience of painful teeth, $9.1 \%$ of high school students had experience of being sore, aching, and painful in the teeth, compared to $4.4 \%$ of middle school students, and showed significant difference $\left(x^{2}=4.23, \mathrm{p}<.05\right)$. As a result of the oral health behavior in middle-and-high school students, $48.6 \%$ of middle school students were indicated to be higher than $26.4 \%$ of high school students in the experience of having ever gone to dentist for the past 1 year, and showed statistically significant difference $\left(x^{2}=24.56, \mathrm{p}<.001\right)$. As for the period of toothbrushing during one day, $68.5 \%$ of middle school students brushed teeth after having breakfast $\left(x^{2}=6.39\right.$, $\mathrm{p}<.05)$ more than $57.3 \%$ of high school students. After having lunch, $16.8 \%$ of high school students brushed teeth more than $7.2 \%$ of middle school students, and showed statistically significant difference $\left(\chi^{2}=10.58, \mathrm{p}<.01\right)$. As a result of judging dental checkup in middle-and-high school students, $44.1 \%$ of high school students had dental caries $\left(\chi^{2}=25.36, p<.001\right)$ more than $22.3 \%$ of middle school students. $9.6 \%$ of middle school students had tooth loss more than $4.1 \%$ of high school students, and showed statistically significant difference $\left(\chi^{2}=5.39\right.$, $\mathrm{p}<.05$ ).
\end{abstract}

Key Words : Middle School students, High school students, oral symptoms, oral health behavior, dental checkup

\footnotetext{
"교신저자 : 정미애(teeth2080@kangwon.ac.kr)

접수일 10년 01월 11일수정일 (1차 10년 02월 10일, 2차 10년 02월 13일) 게재확정일 10년 04월 09일
} 


\section{1. 서론}

우리나라에서 가장 문제가 되는 구강질환인 치아우식 증과 치주질환은 예방이 무엇보다도 중요하며 일단 발생 되면 지속적인 관리가 필요하다[1].. 이러한 구강건강을 파괴하는 치아 상실의 중요한 원인이 치아우식증이며, 학 령기의 충치 발생은 일생을 통해 가장 중요한 문제라고 할 수 있다. 중, 고등학교 시절인 청소년기의 올바르고 지 속적인 구강관리 여부는 성년기와 노년기의 구강건강을 결정한다. 따라서 이 시기는 부모에의 의존도가 큰 아동 기와는 달리 실질적으로 본인의 구강상태를 스스로 책임 지기 시작하는 단계이므로 적절한 교육적 자원이 반드시 필요하다[2]. 특히 제 2 대구치가 맹출하고 영구치열이 완 성을 이루어 평생치열을 완성하는 시기인 중학생의 영구 치 치아우식증 실태 및 구강보건에 대한 행태는 중요하 다고 생각된다. 세계보건기구에서는 지역간, 국가간 연령 비교 시 많이 채택하고 있으며 중시하도록 권고하고 있 다[3].

학교구강보건은 학생의 구강건강을 합리적으로 관리 하고 학생의 구강보건지식과 태도 및 행동을 변화시켜, 일생동안 구강건강을 적절히 관리 할 수 있는 능력을 배 양시켜 주는 계속적 과정[4]이라고 볼 때 이는 최근의 학 교보건의 변화와 연관하여 적절할 사업이라고 생각된다. 지금까지 초등학교 구강보건실태에 대한 연구는 많지만, 중, 고등학생들을 대상으로 한 구강보건실태에 대한 연 구는 드물다.

이에 본 연구는 $\mathrm{S}$ 중학교, S고등학생 1학년 학생들의 문진표 작성결과 및 구강검사결과를 통해 학생들의 구강 보건실태를 평가하고 일생에 중요한 시기인 청소년기의 학교구강보건사업의 지속적 발전을 위한 기초자료로 사 용하고자 한다.

\section{2. 연구방법 및 대상}

\section{1 연구대상}

본 연구는 서울시에 소재한 S중학교 1학년 251명, $\mathrm{S}$ 남 자고등학교 1학년 220명을 대상으로 2009년 6월 20일, 27일, 7월 9 10일 동안 동인병원 검진센터에서 구강검진 을 실시하였다. 치과의사 2 명과 치과위생사 4 명이서 직 접 구강검진을 실시하였으며, 총 471 명을 검진하였다.

\section{2 자료분석}

본 연구의 수집된 자료는 SPSS(Statistical Package for the Social Science) WIN 13.0 프로그램을 이용하여 분석 하였다. 분석기법으로는 연구대상자 학생들의 구강증상 과 구강건강행태, 그리고 구강검사 결과를 알아보기 위해 $\chi^{2}$ (Chi-square) 검증과 빈도분석을 실시하였다.

\section{3. 연구결과}

\section{1 일반적인 특징}

본 연구는 연구대상은 표 1 에서 보는 바와 같이 중학 생 251명, 고등학생 220 명으로 총 471 명을 대상으로 하 였다.

[표 1] 연구대상자의 일반적 특성

\begin{tabular}{|c|c|c|c|c|}
\hline 구 & & 분 & 중학생 & 고등학생 \\
\hline \multirow{2}{*}{ 성 } & \multirow{2}{*}{ 별 } & 남 & $127(50.6)$ & $220(100.0)$ \\
\hline & & 여 & $124(49.4)$ & - \\
\hline & & & $251(100.0)$ & $220(100.0)$ \\
\hline
\end{tabular}

\section{2. 중, 고등학생의 구강증상에 대한 경험 상태}

중, 고등학생들의 구강증상에 대한 경험 상태를 조사 한 결과 표 2 와 같다. 학생들이 치아가 깨지거나 부러진 경험 조사 결과 고등학생이 $14.5 \%$ 로 중학생 $9.2 \%$ 보다 치 아가 깨지거나 부러진 경험이 있었으나 유의한 차이는 아니었다.

학생들이 차갑고 뜨거운 음료 혹은 음식을 마시거나 먹을 때 치아가 아픈 경험이 있는지 살펴본 결과는 고등 학생이 $23.2 \%$ 로 중학생 $14.3 \%$ 보다 차갑고 뜨거운 음료 혹은 음식을 마시거나 먹을 때 치아가 아픈 경험이 있었 으며, 학교급에 따라 유의한 차이를 보였다 $\left(\chi^{2}=6.08\right.$, $\mathrm{p}<.05$ ).

학생들이 치아가 쑤시고 욱신거리고 아픈 경험이 있는 지 살펴본 결과 고등학생이 $9.1 \%$ 로 중학생 $4.4 \%$ 보다 치 아가 쑤시고 욱신거리고 아픈 경험이 있었으며, 학교급에 따라 유의한 차이를 보였다 $\left(x^{2}=4.23, \mathrm{p}<.05\right)$. 학생들이 잇 몸이 아프거나 피가 난 경험이 있는지 살펴본 결과 중학 생이 $14.3 \%$ 로 고등학생 $13.6 \%$ 보다 잇몸이 아프거나 피 가 난 경험이 있었으나 통계적으로는 유의한 차이를 보 이지 않았다.

학생들이 혀 또는 입 안쪽 뺨이 욱신거리며 아픈 경험 조사 결과 중학생과 고등학생이 각각 $98.0 \%, 98.2 \%$ 로 별 다른 차이 없이 혀 또는 입 안쪽 뺌이 욱신거리며 아픈 경험이 없는 학생이 대부분을 차지하였다.

학생들이 불쾌한 입 냄새가 난 경험이 있는지 살펴본 결과 중학생이 $15.9 \%$ 로 고등학생 $11.8 \%$ 보다 불쾌한 입 
냄새가 난 경험이 있었으나 학교급에 따른 유의한 차이 는 없었다.

[표 2] 중, 고등학생의 구강증상에 대한 경험 상태

\begin{tabular}{|c|c|c|c|c|c|c|}
\hline 구 & 분 & Yes & No & 계 & $\begin{array}{l}\chi^{2} \\
\text { (df) }\end{array}$ & $\mathrm{p}$ \\
\hline \multirow{3}{*}{ 치아파절 } & 중학생 & 23 & 228 & 251 & 20 & \multirow{3}{*}{0.070} \\
\hline & & (9.2) & (90.8) & (53.3) & \multirow{2}{*}{ (1) } & \\
\hline & 고등학생 & $\begin{array}{c}32 \\
(14.5)\end{array}$ & $\begin{array}{c}188 \\
(85.5)\end{array}$ & $\begin{array}{c}220 \\
(46.7)\end{array}$ & & \\
\hline \multirow{4}{*}{$\begin{array}{c}\text { 치아 } \\
\text { 지각과민 }\end{array}$} & \multirow{2}{*}{ 중학생 } & 36 & 215 & 251 & \multirow{4}{*}{$\begin{array}{c}6.08^{*} \\
(1)\end{array}$} & \multirow{4}{*}{0.014} \\
\hline & & (14.3) & (85.7) & (53.3) & & \\
\hline & \multirow{2}{*}{ 고등학생 } & 51 & 169 & 220 & & \\
\hline & & (23.2) & $(76.8)$ & $(46.7)$ & & \\
\hline \multirow{4}{*}{ 치아통증 } & \multirow{2}{*}{ 중학생 } & 11 & 240 & 251 & \multirow{4}{*}{$\begin{array}{c}4.23 * \\
(1)\end{array}$} & \multirow{4}{*}{0.040} \\
\hline & & (4.4) & (95.6) & (53.3) & & \\
\hline & \multirow{2}{*}{ 고등학생 } & 20 & 200 & 220 & & \\
\hline & & $(9.1)$ & (90.9) & (46.7) & & \\
\hline \multirow{4}{*}{ 잇몸질환 } & \multirow{2}{*}{ 중학생 } & 36 & 215 & 251 & \multirow{4}{*}{$\begin{array}{c}0.05 \\
(1)\end{array}$} & \multirow{4}{*}{0.826} \\
\hline & & (14.3) & (85.7) & (53.3) & & \\
\hline & \multirow{2}{*}{ 고등학생 } & 30 & 190 & 220 & & \\
\hline & & (13.6) & (86.4) & (46.7) & & \\
\hline \multirow{3}{*}{$\begin{array}{c}\text { 구강 내 } \\
\text { 통증 }\end{array}$} & \multirow{2}{*}{ 중학생 } & 5 & 246 & 251 & \multirow{3}{*}{$\begin{array}{c}0.02 \\
(1)\end{array}$} & \multirow{3}{*}{0.891} \\
\hline & & (2.0) & (98.0) & (53.3) & & \\
\hline & 고등학생 & $\begin{array}{c}4 \\
(1.8)\end{array}$ & $\begin{array}{c}216 \\
(98.2)\end{array}$ & $\begin{array}{c}220 \\
(46.7)\end{array}$ & & \\
\hline \multirow{4}{*}{ 구취 } & \multirow{2}{*}{ 중학생 } & 40 & 211 & 251 & \multirow{4}{*}{$\begin{array}{c}1.65 \\
(1)\end{array}$} & \multirow{4}{*}{0.199} \\
\hline & & (15.9) & (84.1) & (53.3) & & \\
\hline & \multirow{2}{*}{ 고등학생 } & 26 & 194 & 220 & & \\
\hline & & (11.8) & (88.2) & (46.7) & & \\
\hline
\end{tabular}

$* \mathrm{p}<.05$

\section{3 중, 고등학생의 구강건강행태}

중, 고등학생들의 구강건강행태 조사 결과 표 3 과 같 다. 학생들이 지난 1 년 간 치과병원을 간 적이 있는지 살 펴본 결과 중학생이 $48.6 \%$ 로 고등학생 $26.4 \%$ 보다 지난 1 년 간 치과병원을 간 적이 많았으며, 통계적으로도 유의 한 차이를 보였다 $\left(\chi^{2}=24.56, \mathrm{p}<.001\right)$.

학생들이 하루 동안 이를 닦는 시기에 대해 살펴본 결 과 아침식사 전에는 고등학생이 $32.7 \%$ 로 중학생 $25.1 \%$ 보다 아침식사 전에 이를 많이 닦았으나 유의한 차이는 아니었다. 아침식사 후에는 이를 닦는 학생이 중학생이 $68.5 \%$ 로 고등학생 $57.3 \%$ 보다 아침식사 후에 이를 많이 닦았으며, 유의한 차이를 보였다 $\left(\chi^{2}=6.39, \mathrm{p}<.05\right)$. 점심식 사 후에는 고등학생이 $16.8 \%$ 로 중학생 $7.2 \%$ 보다 점심식 사 후에 이를 많이 닦았으며, 통계적으로도 유의한 차이 를 보였다 $\left(\chi^{2}=10.58, \mathrm{p}<.01\right)$. 저녁식사 후에는 이를 닦는 학생이중학생이 $53.4 \%$ 로 고등학생 $47.3 \%$ 보다 점심식사 후에 이를 많이 닦았으나 학교급에 따른 유의한 차이는 없었다. 잠자기 직전에는 중학생이 $52.6 \%$ 로 고등학생
[표 3] 중, 고등학생의 구강건강행태

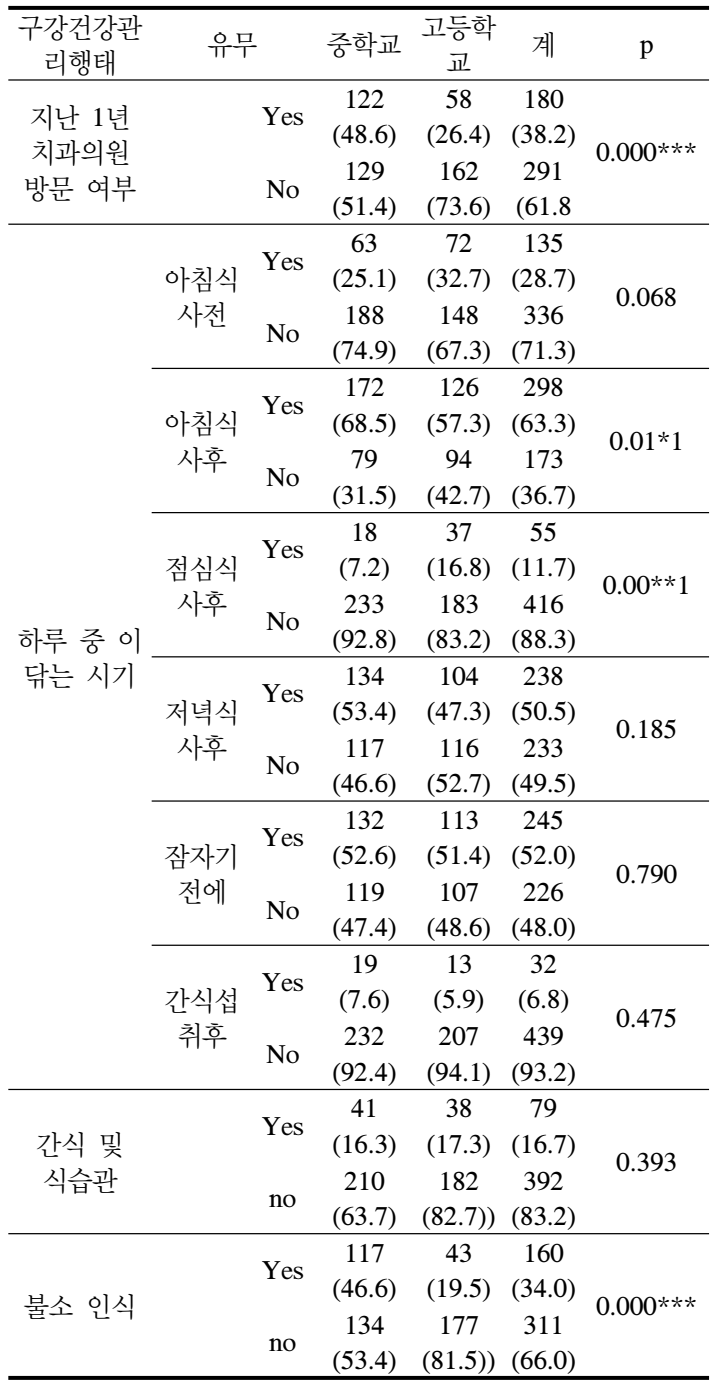

$* \mathrm{p}<.05, * * \mathrm{p}<.01, * * * \mathrm{p}<.001$

$51.4 \%$ 보다 잠자기 직전에 이를 많이 닦았으나 통계적으 로는 유의한 차이를 보이지 않았다. 간식섭취 후에는 중 학생이 $7.6 \%$ 로 고등학생 $5.9 \%$ 보다 이를 많이 닦았으나 유의한 차이는 아니었다.

학생들이 과자 등 단음식이나 콜라 등 청량음료를 즐 겨 먹는지 살펴본 결과는 중학생이 $16.3 \%$ 로 고등학생 $17.3 \%$ 보다 과자 등 단음식이나 콜라 등 청량음료를 즐겨 먹지 않았고, 고등학생은 $63.7 \%$ 로 중학생 $82.7 \%$ 보다 단 음식이나 청량음료의 섭취에 높은 분포를 보였으나 이에 따른 유의한 차이는 없었다.

학생들이 현재 불소가 들어가 있는 치약을 사용하고 있는지 살펴본 결과는 중학생이 $46.6 \%$ 로 고등학생 
$19.5 \%$ 보다 현재 불소가 들어가 있는 치약을 사용하고 있 었고, 고등학생은 $81.5 \%$ 로 중학생 $53.4 \%$ 보다 불소치약 이 무엇인지 모르고 있었으며, 학교급에 따라 유의한 차 이를 보였다( $<<.001)$.

\section{3 중, 고등학생의 구강검사}

중, 고등학생들의 구강검사 결과 표 4 와 같다.

학생들이 우식치아가 있는지 살펴본 결과 고등학생이 $44.1 \%$ 로 중학생 $22.3 \%$ 보다 우식치아가 많았으며, 학교 급에 따라 유의한 차이를 보였다 $\left(\chi^{2}=25.36, \mathrm{p}<.001\right)$.

학생들이 상실치아가 있는지 살펴본 결과는 중학생이 $9.6 \%$ 로 고등학생 $4.1 \%$ 보다 상실치아가 있었으며, 통계적 으로도 유의한 차이를 보였다 $\left(\chi^{2}=5.39, \mathrm{p}<.05\right)$.

학생들이 구내염 및 연조직질환이 있는지 살펴본 결과 는 중학생과 고등학생이 각각 $99.2 \%, 99.1 \%$ 로 별다른 차 이 없이 구내염 및 연조직질환이 없는 학생이 대부분을 차지하였다.

학생들이 부정교합이 있는지 살펴본 결과는 중학생이 $29.5 \%$ 로 고등학생 $25.9 \%$ 보다 요교정 상태였고, 고등학 생은 $74.1 \%$ 로 중학생 $70.5 \%$ 보다 부정교합이 없었으나 통계적으로는 유의한 차이를 보이지 않았다.

[표 4] 중, 고등학생의 구강검사

\begin{tabular}{|c|c|c|c|c|c|c|}
\hline & 구분 & Yes & No & 계1 & $\begin{array}{l}\chi^{2} \\
\text { (df) }\end{array}$ & $\mathrm{p}$ \\
\hline \multirow{2}{*}{$\begin{array}{c}\text { 치아우식 } \\
\text { 증 }\end{array}$} & & $\begin{array}{c}56 \\
(22.3)\end{array}$ & $\begin{array}{c}195 \\
(77.7)\end{array}$ & $\begin{array}{c}251 \\
(53.3)\end{array}$ & $\underset{* *}{25.36^{*}}$ & \multirow{2}{*}{0.000} \\
\hline & 고등학생 & $\begin{array}{c}97 \\
(44.1) \\
\end{array}$ & $\begin{array}{r}123 \\
(55.9) \\
\end{array}$ & $\begin{array}{c}220 \\
(46.7)\end{array}$ & (1) & \\
\hline \multirow{4}{*}{ 상실치아 } & & 24 & 227 & 251 & & \multirow{4}{*}{$0.02 C$} \\
\hline & & (9.6) & $(90.4)$ & (53.3) & $5.39^{*}$ & \\
\hline & 고등학생 & 9 & 211 & 220 & (1) & \\
\hline & & (4.1) & (95.9) & (46.7) & & \\
\hline \multirow{2}{*}{$\begin{array}{c}\text { 구내염 } \\
\text { 밑 } \\
\text { 연조직질 } \\
\text { 환 } \\
\end{array}$} & 중학생 & $\begin{array}{c}2 \\
(0.8)\end{array}$ & $\begin{array}{c}249 \\
(99.2)\end{array}$ & $\begin{array}{c}251 \\
(53.3)\end{array}$ & \multirow{2}{*}{$\begin{array}{c}0.02 \\
(1)\end{array}$} & \multirow{2}{*}{0.895} \\
\hline & 고등학생 & $\begin{array}{c}2 \\
(0.9) \\
\end{array}$ & $\begin{array}{c}218 \\
(99.1) \\
\end{array}$ & $\begin{array}{c}220 \\
(46.7) \\
\end{array}$ & & \\
\hline \multirow{2}{*}{ 부정교합 } & 중학생 & $\begin{array}{c}74 \\
(29.5)\end{array}$ & $\begin{array}{c}177 \\
(70.5)\end{array}$ & $\begin{array}{c}251 \\
(53.3)\end{array}$ & 0.90 & \multirow{2}{*}{0.638} \\
\hline & 고등학생 & $\begin{array}{c}57 \\
(25.9) \\
\end{array}$ & $\begin{array}{c}163 \\
(74.1) \\
\end{array}$ & $\begin{array}{c}220 \\
(46.7) \\
\end{array}$ & (2) & \\
\hline
\end{tabular}

$* * * \mathrm{p}<.001, * \mathrm{p}<.05$

\section{4. 고찰 및 제언}

사람의 심신은 초등학교에 입학하는 시기부터 고등학 교를 졸업하는 시기에 이르는 기간에 가장 왕성하게 성
장하고 이 기간 동안에 학생의 대부분의 생활을 학교에 서 한다. 따라서 학생을 건전한 장래 국민으로 육성하기 위하여 강력한 학교보건이 절대적으로 필요하며 학교보 건의 일부영역인 학교구강보건 또한 중시되어야 한다[5].

학생의 구강건강을 유지 증진시킴으로써 학교생활의 안녕을 기하며, 학교교육의 능률을 향상시키고 학생의 구 강건강 생활태도와 능력을 육성시킴으로써 구강병을 예 방하고 가급적 조기 발견 치료하며, 상실된 치아기능을 회복시켜 주고 구강보건교육을 실시하는 것이다[6].

중, 고등학생의 구강 증상 및 증후를 살펴보면 중학생 은 구취에 대한 증상이 $15.9 \%$ 로 가장 높았으며, 고등학 생은 치아 지각과민 증상이 $23.2 \%$ 로 가장 높게 조사되었 다. 최[9]의 연구에서는 찬음식을 먹을 때 이가 시린 경우 가 $35.7 \%$, 잇솔질을 할 때 이가 시린 경우가 $4.4 \%$ 로 나타 났다. 남[10]의 연구에서는 자신의 구강내에 가장 불편한 점에 대해 중학생의 $24.7 \%$, 고등학생의 $18.0 \%$ 가 “뜨겁고 찬 것에 시리다”라고 조사되었다. 성인의 경우 이가 시릴 때 치아우식증과 치경부마모증을 같이 의심할 수 있으나 고등학생들의 경우 운동량이 많은 시기이므로 충격에 의 한 치아손상이 있을 수 있으므로 치아 손상 여부에 대한 정확한 검진이 필요하다. 중학생은 사춘기성 치은염이 가 장 잘 발생하는 시기인 만큼 구취에 대한 증상이 높게 조 사되었으며, 잇몸질환에 대한 증상도 높게 조사되었다. 사춘기성 치은염 및 잇몸질환에 대한 교육이 필요하다고 사료된다.

최[9]의 연구에서는 지난 한 해 동안 치과병원을 방문 한 학생은 $30.9 \%$ 인 것으로 조사되었으며, 곽[8]은 1년 동 안 치과 이용 횟수에 대해 “없다"는 응답이 $49.7 \%$ 로 가 장 많았으며, $53.3 \%$ 가 2 년 동안 1 회 이상 치과를 이용한 것으로 나타났다. 본 연구에서는 중학생 $48.6 \%$, 고등학생 $26.4 \%$ 가 지난 1 년 동안 치과에 방문하였다. 고등학생에 비해 중학생의 치과방문 비율이 훨씬 높았으며, 최[9]와 곽[8]의 연구에 비해 구강검사를 받는 학생이 많음을 알 수 있다. 앞으로 실시되는 구강검진을 통해 최소한 1년에 한번은 정기적인 치과내원을 할 수 있도록 동기부여하는 역할을 할 필요가 있다고 본다.

학생들의 구강건강행태 조사결과 곽 $[8]$ 은 하루 양치질 횟수에 대해서는 두 번이 $52.7 \%$, 세 번이 $32.9 \%$ 로 응답자 의 $85.6 \%$ 가 하루 2 3회 정도 양치를 하고 있는 것으로 조 사되었다. 최[9]의 연구에서는 아침식사 후가 $33.5 \%$, 잠자 기 전이 $27.2 \%$, 저녁식사 후 $22.0 \%$ 의 순으로 나타났다.

본 연구에서는 중학생은 아침식사 후(68.5\%)에 잇솔 질 시기가 가장 높게 조사되었으며, 저녁식사 후 $(53.4 \%)$, 잠자기 전 $(52.6 \%)$ 순으로 조사되었다. 고등학생은 아침 식사 후 $(57.3 \%)$ 잠자기 전(51.4\%), 저녁식사 후(47.3\%) 
순으로 조사되었다. 중, 고등학생 모두 아침식사 후에 잇 솔질을 하는 경우가 가장 높은 비율을 나타내었다. 중학 생은 저녁식사 후에 대한 잇솔질의 비율이 높은 반면 고 등학생은 잠자기 전에 잇솔질 비율이 더 높게 조사되었 다. 저녁식사 후의 잇솔질도 중요하지만 잠자기 전에 잇 솔질이 더 중요하다고 생각된다. 잇솔질 시기에 대한 교 육시 학생들에게 저녁식사 후와 잠자기 전의 구분이 명 확히 이루어질 수 있도록 저녁식사 후의 음식섭취여부에 따라 잠자기 전 잇솔질의 중요성에 대한 교육이 필요하 고 생각된다.

식습관의 경우 최는 단음식이나 청량음료를 좋아하는 학생은 $43.1 \%$, 좋아하지 않는 학생이 $8.8 \%$ 로 나타났다. 본 연구에서는 중학생들이 과자 등 단음식이나 콜라 등 청량음료를 즐겨 먹는지 식습관에 대해 살펴본 결과 $16.3 \%$, 고등학생 $17.3 \%$ 로 과자 등 단음식이나 콜라 등 청량음료를 즐겨 먹지 않았고, 고등학생은 $63.7 \%$, 중학생 $82.7 \%$ 로 단음식이나 청량음료의 섭취에 높은 분포를 보 였다. 간식 섭취빈도를 결과 5점 만점에 3점 이상인 간식 은 과일, 과자류등 이였으며, 원[7]의 연구에서는 비스켓 과 빙과류의 섭취빈도가 가장 높았으며, 충치가 있는 학 생들은 껌, 탄산음료를 많이 섭취한다고 조사되었다. 탄 산음료를 치아우식증에 대한 저항이 가장 강한 법랑질의 최외층을 용해시키기 때문에 침식에 의해 표면이 거칠어 지면 치아우식발생을 증가시키므로 탄산음료의 치아우식 성에 대한 교육이 필요하다고 사료된다. 또한 식이섭취양 상이 단 것이나 청량음료와 같은 것을 선호하는 식습관 으로 변화해 가는 과정으로 보이며 이에 대한 연령별 식 이섭취양상을 조사하여 올바른 식습관 형성에 대한 교육 이 필요하다.

불소도포 경험에 대해 불소도포를 해보지 않은 학생이 $76.5 \%$ 로 경험 해본 학생들보다 현저히 많았다. 본 연구 에서는 중학생은 $46.6 \%$, 고등학생은 $19.5 \%$ 로 중학생이 불소에 대한 인식이 더 높게 조사되었다. 치아우식증 발 생을 줄이기 위한 방법으로 치면열구전색, 불소도포등이 있으며 고등학생에 비해 중학생의 불소에 대한 인식이 높은 이유는 영구치열과 유치열의 혼합기 시기인 만큼 정기적인 치과방문이 비율이 높아짐으로써 불소에 대한 인식이 더 높게 조사되었다고 생각된다. 학생들에게 불소 에 대한 인식을 높여주고 불소에 대한 교육 및 정보를 제 공하여 올바른 불소사용에 대한 교육이 필요하다고 사료 된다.

곽 [8]의 연구에서는 실제 충치 수는 전체에서 “전혀 없다"가 $36.1 \%$ 로 가장 높았으면 $63.9 \%$ 의 학생이 충치가 있는 것으로 나타났다. 본 연구에서도 정기적으로 치과를 방문하는 중학생들에 비해 고등학생이 충치가 더 많이
조사되었다.

또한 부정교합을 갖고 있는 학생들이 높은 비율을 나 타내었다.

본 연구는 영구치열이 완성되기 시작하는 중학생과 고 등학생의 구강보건행태의 차이를 조사하고, 일생의 중요 한 시기인 청소년기의 구강상태를 조사하여 청소년기의 구강보건을 발전에 이바지하고자 실시하였다.

본 연구 조사결과를 토대로 후속 연구와 교육 실제를 위한 몇 가지 제언을 하면 다음과 같다.

첫째, 본 연구는 중, 고등학생의 구강증상, 구강건강 행태, 구강검진결과에 유의한 차이를 보이고 있다. 중학 생 남여, 고등학생 남자만을 대상으로 연구되어 전체 중, 고생을 대표한다고 보기에는 어려우므로 남,여 중학교, 고등학생 전체를 대상으로 하는 후속 연구가 필요하다.

둘째, 청소년들이 올바른 구강건강행태를 가질 수 있 도록 가정과 학교에서 체계적인 구강보건교육이 이루어 져야 하며, 정기적인 치과방문 및 검진, 올바른 식습관 교육 등을 통하여 청소년기의 치아관리의 중요성에 대한 교육이 절실히 필요하다고 사료된다.

셋째, 구강검진결과 학생들의 구강위생상태는 양호한 편이였으나, 치은염을 가진 학생을 비롯하여 치주질환의 증상을 보이는 학생들이 많았다. 중학생에 비해 고등학생 들이 스케일링이 더 많이 필요하였으며, 스켈링에 대한 정보가 많이 부족하였다. 치은염으로 인한 자가 구취경험 도 많았기 때문에 구취 및 스켈링에 대한 교육이 좀더 많 이 필요하다고 사료된다.

고등학생에 비해 중학생의 구강위생상태가 더 양호하 였기 때문에 앞으로 구강검진 및 교육을 통하여 청소년 기의 구강보건교육에 힘을 기울인다면 앞으로의 청소년 기의 구강건강을 많이 발전되리라 기대하며, 청소년기의 구강건강의 중요성에 대한 교육이 더욱더 필요하다.

\section{참고문헌}

[1] 보건복지부, 구강보건사업계획, pp.3 19, 2007.

[2] 김지영, 일부 고등학생의 구강보건인식도와 Sic Index 조사연구, 한국치위생과학회지, 2006.

[3] 손기찬, 김공현, 김진범, 부산광역시 12 세 아동의 영 구치우식증 실태, 대학구강보건학회지, 제 20 권, 제 2 호, pp.175-187, 1996.

[4] 김종배, 최유진, 공중구강보건학, 고문사. pp.229, 1991.

[5] 김종배 외 6인, 공중구강보건학(8개정), 고문사, 서울, pp. 66 72, 2000. 
[6] 김선숙, 장종화, 중학생의 구강보건행태가 치아우식증 에 미치는 영향, J. of Korean. Soc. of school health, Vol 13, No 2, September, 2000.

[7] Won BY, The study of primary students dieting food make dental caries, oral health care and effection of nutrition education, Department of Food \& Nutrition, The graduate School Sungshin Women's unversity, pp. $102,2002$.

[8] 곽혜정, 김해지역 고등학생의 식행동, 간식섭취 및 치아우식 실태조사, 창원대학교 교육대학원, 석사학위 논문, 2008.

[9] 최충호, 천안북일 남자고등학교 1 학년 학생들의 구강 보건실태에 관한 연구, 순천향의대논문집, 제 5 권, 제2 호, pp. 305 313, 1999.

[10] 김정숙, 남철현, 중등학생의 구강보건에 대한 의식 행태 조사연구, 경산대학교 보건복지연구 소, 보건복 지연구, 제 4호, pp. 207 227, 1999.

[11] 정미애, $\mathrm{S}$ 고교 남학생의 구강검진에 따른 구강보건 행태조사, 한국산학기술학회논문지 제10권, 제9호, pp. 2478-2484, 2009.

[12] 민경진, 도정애, 교정치료 중인 환자의 구강건강영 향지수가 자아존중감에 미치는 영향, 한국 산학기술 학회논문지, 제 10 권 제7호, pp. 1173 1778, 2009.

\section{홍 민 희(Min-Hee Hong)}

[정회원]

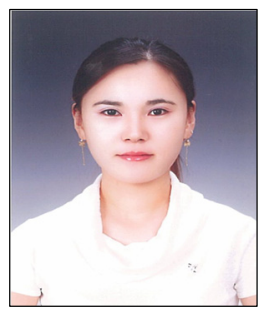

- 2006년 2월 : 건국대학교 생명공 학과 학사 졸업

- 2006년 2월 : 한양대학교 석 . 박사통합과정 입학

- 2009년 2월 : 한양대학교 박사과 정 수료

- 2010년 3월 : 강원대학교 외래교 수

<관심분야>

구강보건학, 생명공학, 노인보건학, 예방치과학

\section{정 미 애(Mi Ae Jeong)}

[정회원]

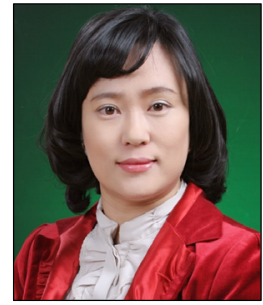

- 1999년 8월 : 단국대학교 보건행 정학과 석사졸업

- 2008년 2월 : 한양대학교 보건학 과 박사졸업,

- 1998년 3월 2009년 2월 : 동 우대학 부교수

- 2010년 3월 현재 : 강원대학 교 치위생과 교수

<관심분야>

보건교육연구, 예방치과학, 노인요양복지학, 보건학 